\title{
DRAWING VS. DESIGN: A STUDY ON INDUSTRIAL DESIGN BSC IN ITALY
}

\author{
Fausto Brevi, \& Flora Gaetani \\ Design Department, Politecnico di Milano (Italy)
}

\begin{abstract}
In Italy, the education on Industrial Design is provided by two categories of institutions: Universities and Academies. The first ones provide a degree course with a strong influence of technical-engineering disciplines (BSc). The Academies have instead a more artistic nature, related to a shapelier aspect of design (BA). These two training paths, while having the same macro objectives, inevitably generate different outgoing profiles.

This study focuses specifically on the BSc students' lack of ability to use drawing to represent the project. This weakness, which is already noticeable within their studies, becomes increasingly evident after graduation, during the portfolio development. Portfolio is the main tool that graduates must submit during selection processes, both professional (job search) and academic (application for admission to higher education courses) when the two profiles (BSc and BA graduated) are in a direct competition.

Indeed, the portfolio, by its very nature, can be much more effective when the projects within it are described through iconographic representation systems such as conceptual sketching and rendering, as well as moodboards and graphs.

The correlation between representation and design disciplines is essential, both in the professional and academic field. Drawing not only plays a central role in the process of "shape - shape perception transmission of shape perception", but also strongly contributes to the creative process of design "idea - idea formulation - idea realization". The continuum that connects these two areas of knowledge is the one that indissolubly connects the medium (drawing) with the aim (designing). It is therefore fundamental to explore the didactics of drawing not only as a separate discipline, but also in relation to the didactics of design.

Therefore, this study explores the relationship between the disciplines of representation and those of design within the BSc and BA in Industrial Design in Italian Schools with the aim of understanding what the current state of art and what future trends are. This critical analysis, based on data published by the Italian Ministry of University \& Research and by each School, will provide the foundations to suggest a proposal of a representation didactics, renovated exploiting also the potentiality available by some innovative teaching techniques.
\end{abstract}

Keywords: Drawing, industrial design, drawing teaching, innovative education, representation.

\section{Introduction}

This study focuses specifically on a supposed lack of ability in using the representation techniques by BSc students in industrial design in the Italian universities. This weakness is already noticeable during their studies and it's in some way facilitated by the selection process setup by universities for the students recruitment, that is based on verifications of theoretical knowledge and not on attitudes or on doing capabilities. At the graduation time this weakness becomes even more evident in the graphical choices used as part of their portfolio.

The portfolio, that is a document collecting the projects developed by students in the frametime they attended the school, is the main tool that just graduated people in Industrial Design must submit during selection processes for being evaluated, both professional (job search) and academic (application for admission to higher education courses). So a portfolio, by its very nature, can be much more effective when the projects within are described through iconographic representation systems such as conceptual sketching and rendering, as well as moodboards and graphs. At the time of selection processes the BSc graduates enter in a direct comparison scenario with BA graduates from art academies, because of the equivalence stated by the Italian law (Equipollenze, 2020) of all the same level degrees, and their weakness in managing the representation techniques stands out more.

We have become aware of this weakness attending evaluation committees in charge to admit candidates to higher education courses. 


\section{Objectives}

In Italy there is a law stating that any same level degree titles, released by any state school (universities, academies, conservatories) or by any private school previously recognized as equivalent, have the same value. In our scenario that means the Industrial Design graduates are equivalent both with a BSc by a technical university or with a BA by an art academy.

Of course the background and the acquired knowledge of these graduates will be different, but we don't care to understand who is better; the industrial design professional world is wide and varied, so probably there are good opportunities for both these professional profiles. We are interested in investigating only one specific aspect, the weakness in managing representation techniques in the technical universities, at first by students and later by graduates, because it could stand for a lack in their skills able to prevent them to be selected in a comparative process.

So the goal of this study is to analyze the main differences in the Industrial Design curricula in the main technical universities and art academies. This analysis is due to the fact that, despite the equivalence of the degree titles, every single school has some space of autonomy in setting up their curricula that have to suit in a predefined framework and to be approved by the state minister in charge for higher education.

The basis of the equivalence for the degrees is that all the same level didactical paths release to students the same amount of academic credits, that is 180 credits for a BSc/BA degree. It's easy to predict there are many differences in the courses setup by universities and by academies around the core that's based for all on the design courses: the surrounding courses can be about technological aspects and/or characters of materials and/or humanistic studies and/or representation techniques and/or history and so on. Here we are looking only at the representation courses and at their relation with design ones.

\section{Methodology}

In order to achieve the set objectives, we used the publication of statistics by academies and universities on the website of the Italian Ministry of University and Research. The Academic Year is 2018-2019 and the numbers of students enrolled for BSc (MIUR, 2020) and BA (MIUR, 2019) have been collected.

The BSc design courses (L-4 and 42) and the BA design courses (DAPL06 and DIPL02) were initially selected. In Italy the category "design" includes all those disciplines related to "aesthetic" industrial production such as product design, communication design, fashion design, furniture design, etc. So, after a first selection of the macro-category "design courses", specific Industrial Design courses were selected according to the course title. Finally, a ranking was made by number of students, a data that identifies which of the schools at national level have the greatest impact on the training of future industrial designers.

We selected a reduced group of universities and academies from the largest until the achievement of $50 \%$ of the global amount of students and we proceeded to analyze each single course through the information on the websites of the institutions and on the Ministry website, dividing the courses into four categories:

- Subjects dealing with the representation for the project: they are courses that deal with drawing, physical modelling, digital modelling, photography, product communication, etc..

- Subjects dealing with the design: all the design workshops and studios.

- Subjects dealing with the professionalization of students and the compilation of a dissertation: they are all the courses and credits both assigned to the final exam, but also to all those subjects aimed at preparing students to enter in the professional world, such as "empowerment".

- The category others include all the theoretical science, humanities, technology and techniques that complement the academic framework.

This categorization was carried out through the course nomenclature, the description of the course program and some interviews with professors teaching in the surveyed schools.

At this point the relative training credits dedicated to the disciplines of representation and those dedicated to the disciplines of the project have been related. 
Figure 1. Enrolled students in A.Y. 2018-2019 at universities (pink) and academies (green). In bold the schools selected for the analysis.

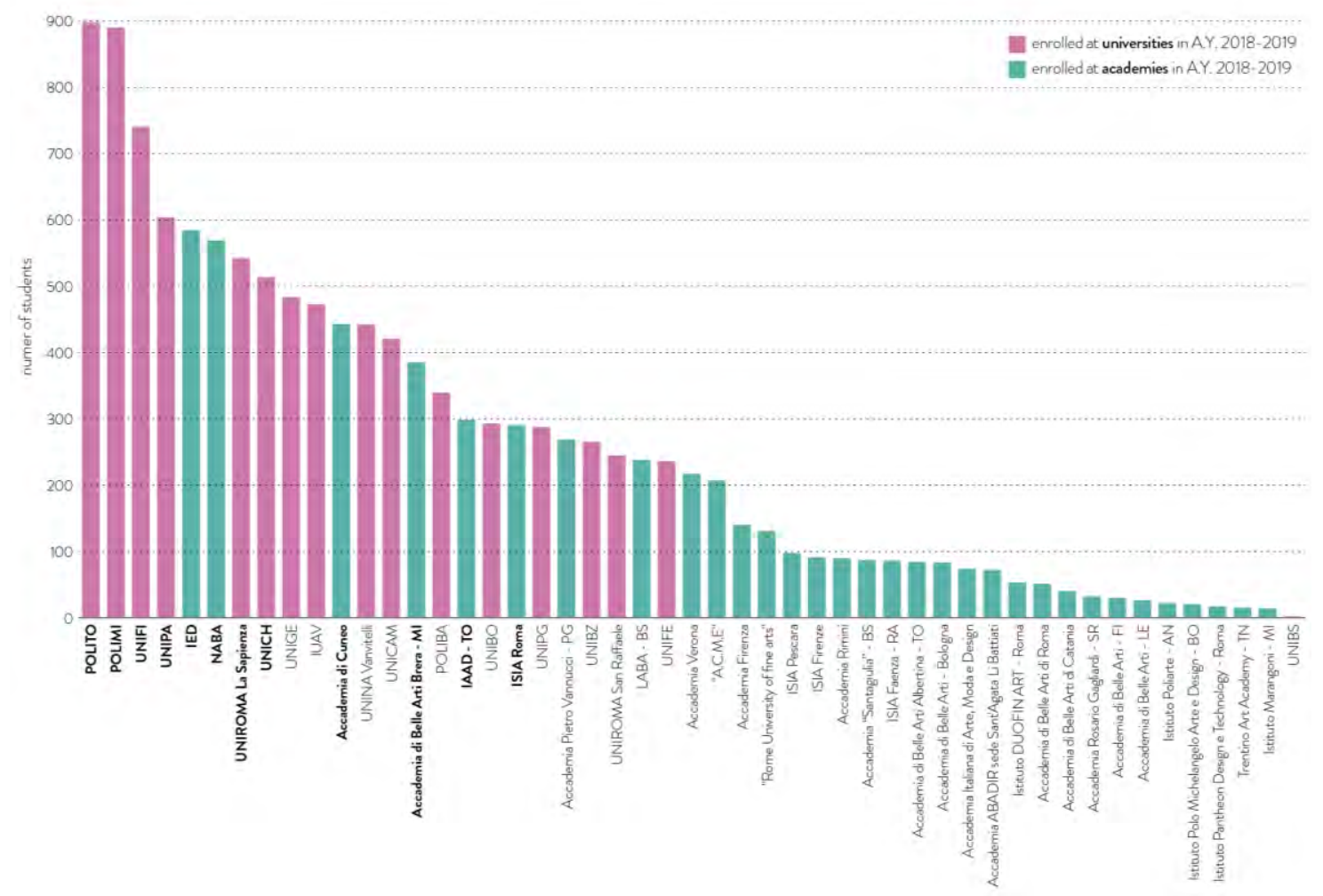

\subsection{Universities vs academies}

In Italy, the peculiarities that distinguish universities and academies are not only about contents, but also, as the numbers show, of other kinds. First of all, it must be pointed out that, in the field of Industrial Design, the universities are all state universities while the academies are mostly private schools.

Moreover, the number of total universities (16) is much lower than the number of academies (32), although they manage, in the Industrial Design field, a much higher number of students (universities 7678 vs. academies 4859). Despite this, in both the sum of enrolled students in the six larger schools registers more than $50 \%$ of global students.

Moreover, a further characteristic is that, due to their being predominantly private schools, the academies usually have several locations scattered throughout the country. In spite of this, the numbers of all the locations were taken into account in the survey because the teaching methods adopted in each location is common.

It should be pointed out that there are a certain number of private schools that do not have (by choice or lack of requirements) an equal certification of which it is not possible to know the numbers and programs because they are not published.

\section{Results}

The results of the recording are summarized in Figure 2. Overall, universities have a lower number of credits dedicated to representation, but a higher number of credits dedicated to project subjects. The difference between the credits dedicated to representation is relevant: an average of 29.5 credits for universities against 42.23 credits for academies. The difference between the credits for the subjects dedicated to the project is smaller: for universities they are 60.33 , for academies 53.83 .

In general, if we observe Figure 2, we can see a greater uniformity in the behavior of academies, more concentrated in a restricted area of the graph, compared with universities which are in scattered positions. 
Figure 2. Relationship between the credits dedicated to the representation (on the abscissa) and those dedicated to the project (on ordinates). The solid lines represent the average values of credits dedicated to the representation (vertical) and credits for the project (horizontal). The bubbles dimension represents the different number of enrolled students.

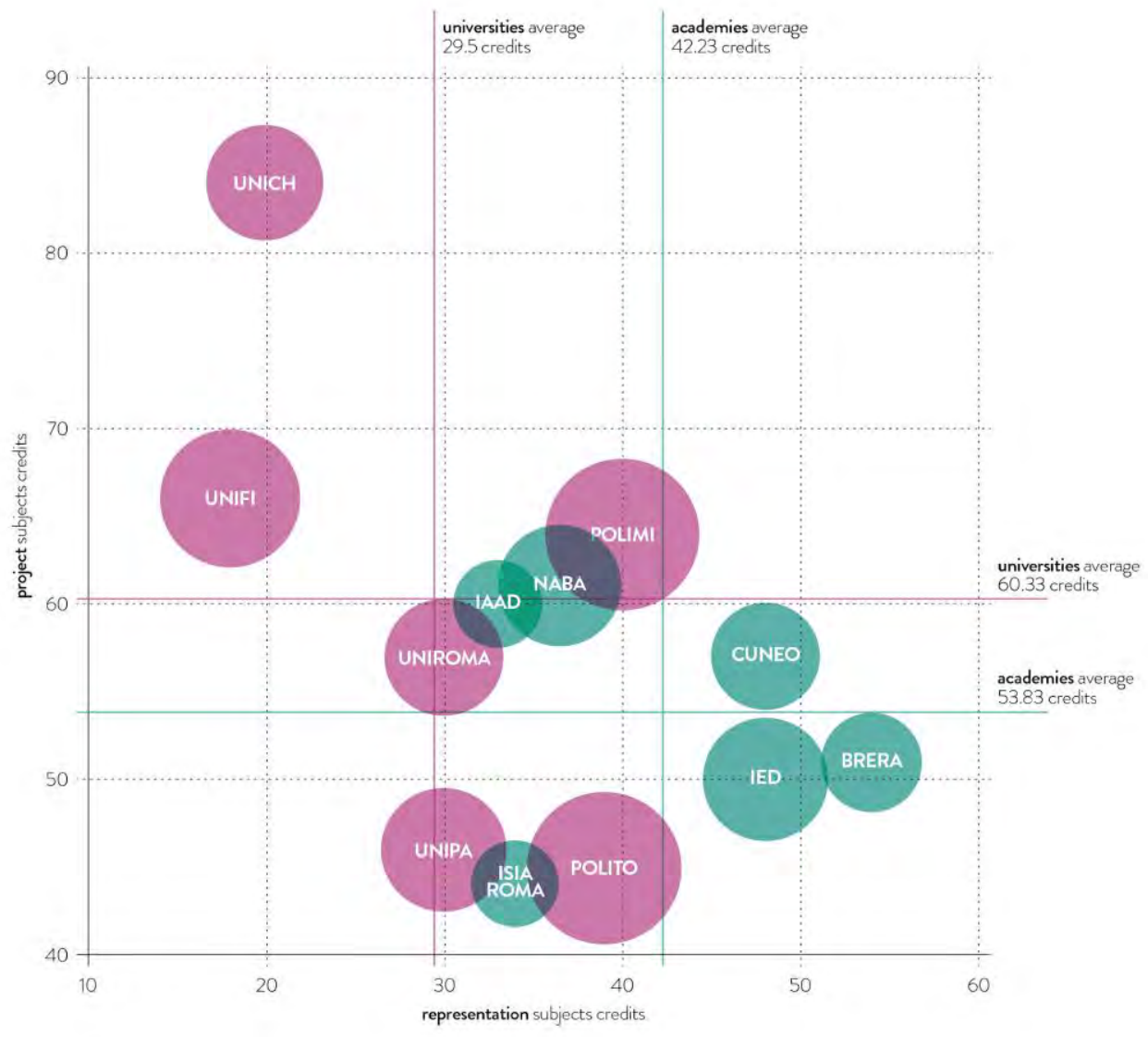

In academies you can read a compact core represented by IED, Cuneo and Brera, which are also the three schools with the highest number of credits dedicated to representation. We find a second nucleus (NABA and IAAD) and, at last, ISIA in Rome which differs from the other academies with the lowest number of credits dedicated to the project. Despite the more scattered positions of universities, we can find a central nucleus created by the Politecnico di Torino, Politecnico di Milano and the Universities of Palermo and Rome. Florence, but above all Chieti-Pescara, are detached from the group with a lower number of subjects dedicated to representation and with a higher number of credits dedicated to the project (Chieti-Pescara in particular, with 84 credits against a general average of 57.08).

Figure 3. Pie charts with the subdivision of the four categories: representation, project (green), others and others.
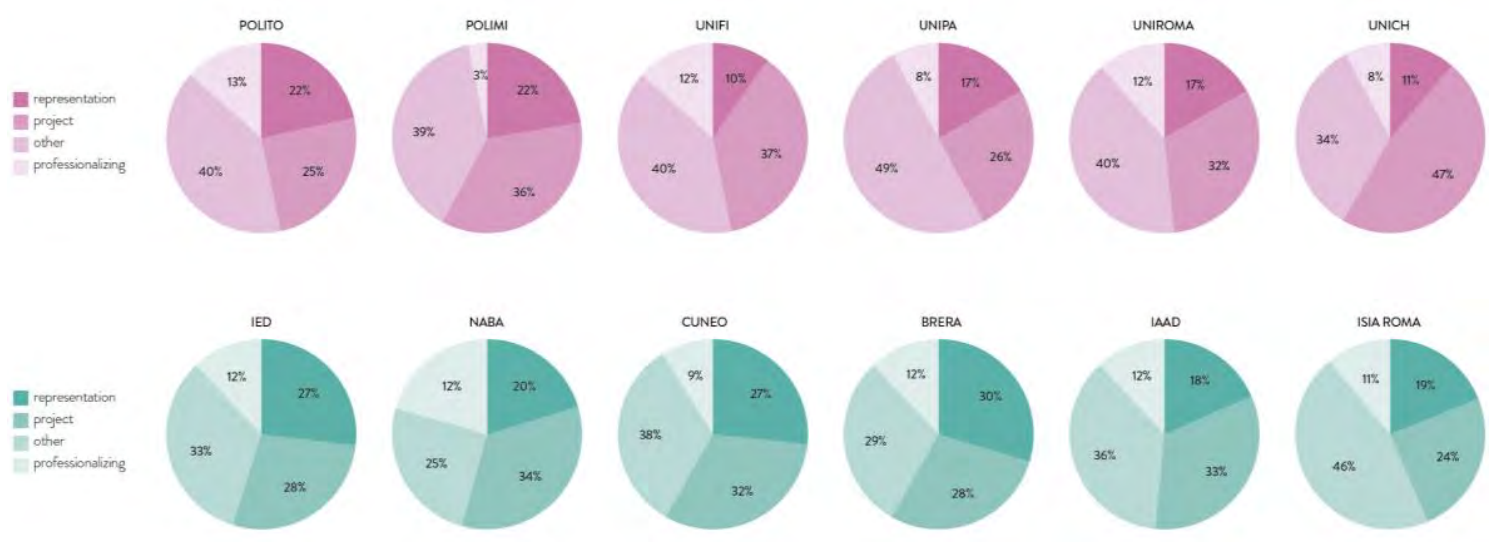
Let us now look at figure 3 which represents the division of the curricula of the schools into the four categories used. In this case it is interesting the behaviour of the schools in the other two categories not analysed in the previous graph: the subjects dedicated to the students professionalisation and the category "other". In academies, on average, more credits are dedicated to professionalizing subjects than in universities; in universities, on the other hand, more credits are dedicated to other courses. In particular, there is a very low percentage of professionalizing subjects at the Politecnico di Milano.

\section{Discussion}

The quantitative (number of participants for the selection of observed schools) and qualitative (evaluation of the courses dedicated to four analyzed categories) confirmed the trend towards a more artistic approach and therefore linked to the subjects of representation by academies. The credits of the subjects related to the project are not so different between academies and universities: this means that students dedicate equal commitment in both types of schools.

Furthermore, an analysis of the training courses shows that the difference in the credits dedicated to the subjects of representation, as concerns universities, is balanced by a greater number of credits dedicated to scientific and technological subjects. In fact, in the number of credits in the "other" category there are both humanities and technical-scientific subjects. In academies, on the other hand, the subjects in the "other" categories are mainly of a humanistic nature, more characteristic of artistic teaching.

The difference in the output profile between the two types of schools can also be found in a greater attention of academies to provide the tools for jumping into the professional world, measured by the amount of credits dedicated to this category. Therefore, the analysis carried out shows that the difference between the two institutions also lies in the attention to the professionalizing subjects and not only in the greater attention for representation subjects. It is also assumed that this can improve the appearance of the portfolio and its maturity.

On the other hand as their curriculum is strongly multidisciplinary, just graduated people in BSc have a greater maturity in dialoguing with all the actors involved in the industrial design process (including the technical ones) and understanding all phases of the process. This characteristic is especially appreciated during the internship phases, but it is hardly noticeable by the companies during the interview, if not with more specific questions.

In general this study confirms the basic assumptions by adding a finer analysis of the other subjects and not only of the two main axes analyzed of representation and design, opening the possibility to further research.

The paper is the result of common research and findings undertaken by the authors. Nevertheless, section 1 and 2 was edited by Fausto Brevi; sections 3, 4 and 5 were edited by Flora Gaetani.

\section{References}

Cocchiarella, L. (2009). Disegno e design. Temi, forme, codici, esperienze. Milan: Città Studi.

Cross, N. (2000). Designerly ways of knowing: design discipline versus design science. Design plus research proceedings, pp. 43-47.

Cunliffe, L. (1999). Learning how to learn, Art education and the background. NSEAD 1999, pp. 115-121.

Equipollenze tra titoli accademici italiani ai fini della partecipazione ai concorsi pubblici. (2020) Retrieved March 21, 2020, from: https://bit.ly/2XvAR3R

Gaetani, F. \& Brevi, F. (2011). Drawing for product design. A training framework in drawing for university students. ICERI2011 Proceedings, pp. 3796-3804.

Gedenryd, H. (1998). How designers work: making sense of authentic cognitive activity (Doctoral dissertation, Lund University). Retrieved from: https://bit.ly/2LTRkK5

Maldonado, T. (1991). Disegno industriale: un riesame. Milan: Feltrinelli.

MIUR (Ministero dell'Istruzione dell'Università e della Ricerca). (2019). AFAM_Iscritti nei corsi accademici. Retrieved from: https://bit.ly/3eiNLcA

MIUR (Ministero dell'Istruzione dell'Università e della Ricerca). (2020). Iscritti per corso di studi - a.a. 2018/19. Retrieved from: https://bit.ly/3c132x1

Oxman, R. (1999). Educating the designerly thinker. In Design Studies 20, pp. 105-122.

Penati, A. \& Seassaro, A. (Eds.). (2000). Didattica\&Design: processi e prodotti formativi nell'università che cambia. Milan: POLI.design

Shön, D.A. (1983), The reflective practitioner. New York: Basic Book. 